\title{
O DIREITO ITALIANO: HISTÓRIA, INFLUÊNCIA E LEGADO
}

\section{doi> 10.33726/akdpapers2447-7656v9a62020p90-122}

PELICANO, Henrique José Rosa

ATIQUE, Wadi ${ }^{3}$

RESUMO: O objetivo do presente texto é o de apresentar e descrever as circunstâncias históricas, culturais e sociais que deram origem a certos princípios gerais do Direito. Para realizarmos esta proposta, optamos pelo aporte metodológico da revisão bibliográfica, em função da riqueza que os acervos físicos e digitais concentram sobre 0 assunto. $O$ interesse pela investigação de um tema como o nosso, prende-se ao fato de que, na condição de estudante das ciências jurídicas, em concomitância com as Ciências Humanas, é praticamente uma condição obrigatória a aproximação de leituras de cunho histórico, social, político e filosófico, que sejam capazes de imprimir maior substância aos conteúdos e análises técnicas postas em prática no mundo das leis. Fundamentam prioritariamente nossa escrita, obras consagradas que tratam da história italiana e, sobretudo, as que se atém a aspectos formadores do Direito Romano. Como resultado desta abordagem, nos foi possível construir uma visão panorâmica e bastante ampla sobre o paradigma sociocultural que envolve a Itália e seus postulados sociológicos, filosóficos e legais.

PALAVRAS-CHAVE: História da Itália, Direito Romano, Principiologia

ABSTRACT: The purpose of this text is to present and describe the historical, cultural and social circumstances that gave rise to certain general principles of law. To carry out this proposal, we opted for the methodological contribution of the bibliographic review, due to the wealth that the physical and digital collections concentrate on the subject. The interest in investigating a topic such as ours is due to the fact that, as a student of the legal sciences, in conjunction with the Humanities, it is practically a mandatory condition to approach readings of a historical, social, political nature and philosophical, that are capable of giving greater substance to the contents and technical analyzes put into practice in the world of laws. Our writing is primarily based on consecrated works that deal with Italian history and, above all, those that focus on aspects that form Roman law. As a result of this approach, we were able to build a panoramic and very broad view of the socio-cultural paradigm that involves Italy and its sociological, philosophical and legal postulates.

KEYWORDS: History of Italy, Roman Law, Principiology

\footnotetext{
${ }^{1}$ Artigo derivado de Trabalho de Conclusão de Curso, apresentado ao Centro Universitário de Rio Preto UNIRP (2018), por ocasião da Graduação no Curso de Bacharelado em Direito, escrito e defendido em banca de avaliação, sob a orientação do Prof. Wadi Atique. Do TCC, então, intitulado "O DIREITO ITALIANO: HISTÓRIA, INFLUÊNCIA E LEGADO", originaram-se este homônimo e outro Artigo, intitulado "A MORAL E A ÉTICA ROMANA ASSIMILADA PELOS POSTULADOS JURÍDICOS", incluso na Revista AKEDIA - Versões, Negligências e Outros Mundos, vol. 10, $2^{\circ}$ sem. de 2020.

${ }^{2}$ Bacharel em Direito / UNIRP. Especializando em Direito Ambiental. Graduando em História. Bacharel em Ciências Biológicas pela UNESP, Universidade Estadual Paulista Júlio de Mesquita Filho, campus de São José do Rio Preto, IBILCE (2012).

${ }^{3}$ Docente na Sociedade Rio-pretense de Ensino e Educação / UNIRP.
} 


\section{INTRODUÇÃO}

O presente estudo se propõe a promover uma exposição sobre o Direito Italiano, no que aqui corresponde não tão somente ao Direito posto, mas ao legado e à herança sociocultural que a Itália, como expressão geográfica atemporal, propiciou e ainda fornece ao mundo, seja no âmbito estritamente jurídico, religioso ou interdisciplinar.

Neste sentido, o presente estudo objetiva abordar os princípios do Direito Romano e sua influência ainda viva e atuante na contemporaneidade. Justifica a realização de um trabalho como este, o fato de que é consenso entre os pensadores e operadores do Direito, que os costumes e princípios são importantíssimos como formadores das fontes de substância e de jurisprudência.

Assim, recuperamos conteúdos da lendária fundação de Roma até a realeza da Roma Monárquica. A partir deles, é que veremos que foram instaurados e ampliados os primeiros esboços dos princípios e costumes do povo romano, o qual deixaria talvez como o maior de seus legados o próprio Direito Romano.

Sem redundância, sabe-se que a Itália foi o berço para a germinação desses conceitos, bem como palco de inúmeras guerras e disputas que enriqueceram e diversificaram a cultura e o modo de vida dos italianos. 0 Belpaese é ainda hoje uma referência de cultura milenar, cujas raízes podem ser detectadas desde sua fundação.

Os sabinos ${ }^{4}$ influenciaram fortemente os costumes religiosos, enquanto que os etruscos ${ }^{5}$ se destacaram por serem muito singulares, especialmente se comparados aos demais povos itálicos, especialmente quanto ao idioma e a notável habilidade para as artes e o comércio.

Já, os romanos, eram o expoente dos sucessos e conquistas militares. No entanto, chega a ser surpreendente que nasça desta turbulenta e intensa contingência histórica e geográfica, a consolidação de uma primeira unidade cultural. Este corpus cultural, mesmo que incipiente, já é dotado de

\footnotetext{
${ }_{5}^{4}$ Antigo povo itálico, habitantes da região do Lácio. ${ }^{5}$ Idem.
} 
costumes, princípios e leis. O aparato legal, por sua vez, é nitidamente influenciado pelos diferentes reinados e pela forma como os reis conduziram a civilização romana de outrora.

Trata-se, assim, de um estudo de grande importância para a História do Direito e para as origens dos atuais direitos, especialmente no tocante ao escopo do Direito Civil e Processual Civil. Conhecimentos desta natureza podem tornar o profissional muito mais do que apenas um operador do Direito, pois lhe conferirá robustez e ciência de quais razões e por quais motivos as aplicações do Direito são realizadas.

Para realizamos tal empreitada, empregamos a metodologia da revisão bibliográfica, precipuamente em suas línguas-mães e, no entanto, sem prejuízo das versões traduzidas quando não encontradas as originais.

Por conseguinte, este trabalho porta como resultado, um compilado de explanações, comparações, análises, questionamentos e exemplos que tornam mais evidentes as relações que entrecruzam um passado que brilhantemente persiste, ao mesmo tempo em que influencia e ensina.

\section{HISTÓRIA DO DIREITO E DO POVO ROMANO}

O Direito Romano é uma matriz. É o terreno que sustenta os Direitos do homem, desde Estados como a República Federativa do Brasil, como até o longínquo Império do Japão 6 . O próprio vocábulo "direito", por exemplo, provém do latim, idioma oficial da Roma Antiga, muito empregado no jargão científico contemporâneo e utilizado nos limites do Vaticano.

A origem dele, do Direito Romano, é rica e, partindo do latim mais modernizado, podemos elencar principalmente duas variantes linguísticas que a ele se vinculam: a) De Directus ${ }^{7}$, (conjugado como tempo passado de

\footnotetext{
${ }^{6}$ Neste sentido, é de grande valia consultar obras como: "SHINJITAI: Constituição do Japão, 1947”. Nesta, se verifica, no corpo do referido diploma, influências do Direito Romano pulverizadas, especialmente a partir do capítulo III. Outra publicação valiosa é a de: "NISHITANI, Yuko. Introdução à História do Direito Japonês. Revista Cadernos do Programa de Pós- Graduação em Direito. Universidade Federal do Rio Grande do Sul, 2003. p. 84”. Em ambas, podemos notar que a influência dos legados jurídicos de Roma é colossal.

${ }^{7}$ HOUAISS Antonio, Villar, Mauro de Salles. Houaiss, Dicionário de Língua Portuguesa. Editora Objetiva, 2009, p. 690.
} 
"dirigere"), o qual se refere a um conjunto de regras pré-estabelecidas a serem rigidamente seguidas; e, b) Aquela acepção donde se deriva a expressão "De Rectus", por meio da qual se consagra a imagem da Deusa da Justiça segurando uma balança com um fiel, dizendo ao mundo que só haverá justiça (Justitia) quando a posição do fiel estiver na posição de "rectus", isto é, perpendicular ao solo ${ }^{8}$.

Interessante ainda que se considere que vários vocábulos jurídicos usem o mesmo radical ou se norteiem pela expressão "Jus / lus / ou Ivs", que era a terminologia empregada primordialmente no latim clássico pelos romanos, exatamente para se referir precipuamente ao "Direito Objetivo".

Quanto à divergência das três grafias, explica-se que, à época, havia uma confusão entre as letras "U" e "V", com prevalência fonética daquela sobre esta. Ao que não se estranhe a letra "J" ser lida como "I", vez que em vários dialetos da Itália atual ainda se mantém a regra, tal como em piemontês, e.g., o vocábulo "Juventus" (lido luventus, com i).

Da abrangência da própria etimologia de Directum, já é possível extrair uma primeira influência da pungente herança de Roma a partir da configuração da linguística românica. Sabe-se, portanto, que o latim influenciou e originou diversas outras línguas. É, por sua vez, o latim "la pietra d'angolo" (a pedra angular), pela qual se assentaram vários ramos linguísticos pela Europa e pelo mundo afora.

Se assim não fosse, restaria infundada a origem românica do italiano, do espanhol, do romeno e até mesmo do próprio português. Soma-se a isto, o fato de que o idioma de Roma se mesclou em outros Estados, influenciando-os fortemente, os quais vão do muito latinizado/originado francês até mesmo ao alemão, descaracterizando sobremaneira o latim.

Elenque-se, e.g., pois, algumas derivações principais de "directum": em português, direito; em italiano, diritto ${ }^{9}$; em espanhol, derecho ${ }^{10}$; em francês, droit $^{11}$.

Assim, quando se considera como elemento constituinte de uma

\footnotetext{
${ }^{8}$ Esta informação se faz referenciar em: "CRUZ, Sebastião. Jus Derectum (Directum). Coimbra, 1971 Apud FERRAZ Jr., T.S. Introdução ao Estudo do Direito. Atlas, 1988. p. 557”.

${ }^{9}$ COLLINS, Willian et al. Collins Italian Dictionary. Harper, 2007, p. 53.

${ }^{10}$ COLLINS, Willian et al. Collins Spanish Dictionary. Harper, 2006, p. 65.

${ }^{11}$ LAROUSSE. Petit Dictionnaire de Français. Larousse, 2004, p. 258.
} 
sociedade o idioma, vê-se que o latim conquistou, reformou e atuou em diversas regiões, especialmente europeias, portando também elementos culturais: dos teatros e fanfarras de ruas, ao academicismo do Direito.

Mas, afinal, ao par desta construção de linguagem donde os direitos e garantias descendem, o que, então, se entenderia por Direito Romano? Matos Peixoto ${ }^{12}$, em seu Curso sobre Direito Romano nos assegura que: "Conjunto de normas jurídicas que regeram o povo romano em várias épocas de sua História, desde as origens de Roma, até a morte de Justiniano, Imperador do Oriente, em 565 da Era Cristã", deram feição não apenas linguística ao Direito, mas, sobretudo, sociocultural.

Ao lado disso, o historiador Marrou ${ }^{13}$ afirma que surgia associadamente ao Direito Romano, uma nova forma de cultura. Neste átimo, amplia-se a perquirição de qual estirpe seria exatamente esse povo romano. A resposta se encontra nas raízes da própria origem de Roma, com as primeiras civilizações da Lazio (Lácio), com todos aqueles atingidos pela expansão do maior Império que a humanidade já fez face.

No entanto, o tratamento para com os cidadãos romanos seguia uma separação, nutrindo o privilégio de uns sobre a lamúria de outros. Ressaltese que, para a acepção do conceito de povo romano, considerar-se-á aqui, o todo atingido pela cultura romana.

É o caso dos "Gaulois", que embora fizessem frente aos conquistadores romanos, acabaram sucumbindo ao poderio do Império. A antiga Gália, configurada hoje pelos franceses, era considerada o lar de povos bárbaros, com expoente no lendário Vergincetorix. No entanto, é factual o entendimento de que o povo francês (na própria Paris) bebeu das fontes de Roma. Não obstante à frase que confere a geminação das cidades: "Solo Parigi è degna di Roma; Solo Roma è degna di Parigi" - "Seule Paris est digne de Rome; Seule Rome est digne de Paris" (Só Paris é digna de Roma / Só Roma é digna de Paris).

Os romanos eram práticos. Quando traçado o paralelo com a

\footnotetext{
${ }^{12}$ Ver: PEIXOTO, José Carlos de Matos. Curso de Direito Romano. Tomo I: partes introdutórias e geral. Rio de Janeiro: Renovar, 1997, p. 03.

${ }^{13}$ MARROU. As Escolas Romanas. In: História da Educação na Antiguidade. São Paulo: Herder, 1966.
} 
civilização grega, é ainda mais nítida a diferença da forma de lidar com as questões mais elementares da vida. O espírito grego perquiridor e racional propunha um antagonismo natural ao que se via na forma romana de se viver. Da Grécia surgiram pensadores de grandezas astronômicas, como Pitágoras, Euclides, Aristóteles, Sócrates, Platão, Heráclito, Parmênides, Demócrito e Arquimedes. Note-se que o Sul da Itália foi fortemente influenciado por gregos (antiga Magna Grécia). Inclusive o próprio Arquimedes nasceu em solo italiano, Siracusa, na Sicília. Assim, durante os primórdios das civilizações ocidentais, os grandes pensadores, ainda que nascidos na Itália (da expressão geográfica) eram gregos.

A título de curiosidade, o povo italiano é considerado altamente miscigenado. Os italianos do norte se apresentam com características mais próximas dos nórdicos, enquanto que, quando se ruma ao Sul, há a presença de caracteres mais gregos e mouros. Atualmente, devido à evolução natural da natureza humana, as diferenças vão diminuindo.

Mas, desta praticidade da península Itálica de outrora, pautavam-se fundamentalmente em três princípios, que são cruciais para o entendimento do Direito Romano. Giordani ${ }^{14}$, em sua excelente obra, os elenca com maestria. São eles: a Gravitas, a Pietas e a Simplicitas.

\section{II.1. Gravitas}

Trata-se substancialmente de uma virtude enaltecida pelo povo romano. Em sua literalidade, trata-se do termo que se traduz pela palavra "peso". Deriva-se também de Gravitas a extraordinária análise do inglês Sir Isaac Newton, quando enunciou as suas Leis da Gravidade.

Gravitas, portanto, é um estado atinente dos indivíduos enraizados em honra e renúncia em decorrência ao estrito dever moral. É possível associar o sentido de Gravitas ao contexto dos Estoicistas, ou ainda como elemento do qual os Epicuristas se despiram. É o que se remete a um ser de

\footnotetext{
${ }^{14}$ GIORDANI, Mário Curtis. Iniciação ao Direito Romano. $3^{\text {a }}$ Edição, Editora Lumen Juris. 1996, p. 01.
} 
compromisso e de seriedade ${ }^{15}$.

Nos costumes de Roma, associa-se o termo Gravitas ao autocontrole. Neste diapasão, ainda em tema de valores da sociedade romana, existe outra virtude associada à Gravitas, trata-se da Constantia $^{16}$. Um termo que se projeta um pouco abstrato em um primeiro momento, no entanto, não são necessárias incisões tão cirúrgicas para que o pensamento atual consiga identificar Constantia. De forma intuitiva, remete-se ao termo em português "Constância". E a tradução pode ser assim definida. Pois, de fato, o romano deveria manter uma calma e serenidade constantes. Essa determinação e perseverança é ao que se referem os romanos com o termo Constantia.

Do cinema, pode-se extrair um pouco da condição romana de Gravitas e Constantia, ao observar o General Maximus Decimus Meridius, interpretado brilhantemente por Russel Crowe, no filme Gladiador. Ou ainda, dos contos do Cônsul Múcio Escévola ${ }^{17}$, em especial do rei etrusco Lars Porsenna.

\section{II.2. Pietas}

Uma virtude romana que permanece extremamente presente na sociedade italiana e na comunidade italiana e italófila de todo o planeta, é o sentimento de piedade, de compaixão.

Assim, literalmente traduzida, o palavra Pietas é lida como expressão do sentimento de "Piedade", em português. Aliás, de todas as línguas românicas, a mais próxima - por diversas razões, algumas bastante óbvias é o italiano. Portanto, não é de se surpreender que Pietas, na língua do Belpaese se diga "Pietà".

Aos versados em arte, talvez se revolva a memória da estátua da "Pietà", do genial artista Michelangelo di Lodovico Buonarroti Simoni, localizada na Basílica de São Pedro, no Vaticano. Trata-se de uma estátua, considerada por esmagadora maioria, como sendo a mais famosa e bela de todos os tempos, em que se vê Cristo, morto, nos braços da Virgem Maria.

\footnotetext{
${ }^{15}$ APPUZO, Michael L.J. M.D. Gravitas, Severitas, Veritas, Virtus. Neurosurgery. August, 2006 volume 59 - issue 2, p. 219-221. doi: 10. 1227/01. NEU. 0000309836.57544.B0

${ }^{16}$ WARD, A., Heichelheim, F., Yeo, C. A History of the Roman People. $4^{\text {a }}$ Edi. Nova Jérsei: Prentice Hall, 2003, p. 57-58.

${ }^{17}$ TITO LÍVIO. Ab Urbe Condita. II.
} 
Já se citou a importância da Itália para com o cenário mundial. Mas, desta simples referência a uma estátua, pode-se extrair pelo menos três gigantescas influências daquela cultura:

a) A Arte. Inquestionável, basta que se venha à mente nomes como Leonardo da Vinci, o próprio Michelangelo Buonarroti e outros brilhantes artistas, de todas as formas de artes que a Itália trouxe ao mundo. Ingenuidade seria, que somente o Renascimento fosse palco desse florescimento constante.

b) O Catolicismo Apostólico Romano. A Igreja mais poderosa do mundo, com maior número de fiéis, autônoma, de riqueza histórica, cultural e religiosa inestimável, de influência política imensa. O Bispo de Roma, o Papa, é uma das figuras mais poderosas do planeta. Tudo isso se consolidou com uma administração feita à Italiana. É inegável que também uma instituição de tão alto nível não desenvolvesse uma forma de Direito. $\mathrm{E}$, assim se sucedeu: o Direito Canônico. Novamente, fortíssima é a presença do latim. Tanto que se origina aqui o denominado latim eclesiástico.

c) Pietà. Agora, referida como a virtude romana. Pietas, para os romanos, pode ser entendida hoje como devoção. Além do possível corolário da própria etimologia, aponte-se para que essa devoção era um liame de compromisso sincero e puro. O romano incumbia-se no dever de prover, ser fiel e curar pela divindade e pela família ${ }^{18}$. Pietà era, então, um dever de moralidade e profundo respeito para com a família, a pátria e Dio. Trata-se de uma característica marcante do povo italiano: o nacionalismo (embora com divergências internas entre suas regiões), a devoção religiosa (em especial, o Catolicismo Romano) e o amor e entrega pela família.

Em uma sociedade que surgiu predominantemente de modo paternalista, a figura do homem era mais comumente utilizada para a referência dessas virtudes. Arrolavam-se nela também heróis que seriam os exemplos e modelos desta sociedade. No caso de Pietas, o herói mais relacionado para estampar essa virtude era Enéias, de Eneida ${ }^{19}$.

Vê-se também o senso de devoção à família se impor, inclusive em associações criminosas italianas. Especialmente as do Sul, em que há pelo menos três grandes grupos mafiosos. O código de ética da máfia italiana

${ }^{18}$ ADKINS, L.\&ADKINS, R. Dictionary of Roman Religion. New York: Oxford University Press, 2000, p. 180.

${ }^{19}$ CÍCERO. De Natura Deorum.1.116. 
enaltece o conceito de família. E é novamente, pelas mídias do cinema, na Clássica Saga "O Poderoso Chefão", II Padrino, Don Vito Corleone, diz: "Um homem que não se dedica à família, jamais será um homem de verdade".

Quanto ao pensamento nacionalista italiano, não se pode enquadrá-lo tão somente num cenário romano, ou mesmo circunscreve-lo aos eventos das grandes conquistas. Viu-se Roma conquistar uma miríade de povos, com um exército muitíssimo estruturado e cujas estratégias são ainda referências para a organização militar dos dias atuais (assim como as estratégias políticas italianas, com ápice na obra de Niccolò di Bernardo dei Machiavelli).

O próprio Maquiavel, em o "O Príncipe", soube apontar aos "italianos" que sua grandeza seria de grande valia para evitar as investidas que a Velha Bota vinha sofrendo ${ }^{20}$. E uma das virtudes de excelência do exército romano era a Disciplina, acompanhada de uma ideia de unidade.

Essa mesma unidade sofrera um impacto durante a evolução da história italiana, no entanto, a letra do Hino Nacional da Itália, o chamado "Canto degli Italiani" (Canto dos Italianos) ou "Inno di Mameli" (Hino de Mameli), é bem claro em sua primeira estrofe, senão, veja-se:

Fratelli d'Italia (1); L'Italia s'è desta (2); Dell'elmo di Scipio (3), S'è Cinta la Testa (4); Dov'è la Vittoria? (5); Le porga la Chioma (6); Che Schiava di Roma (7); Iddio la Creò (8)." "Stringiamoci a Coorte (9), Siam' Pronti alla morte! L'Italia Chiamò! (10)"

Pode-se traduzir a primeira estrofe do "Inno di Mameli", como uma referência expressa à grandeza de Roma. Trata-se de exaltar um espírito nacionalista, clamando a grandeza romana e, nas estrofes subsequentes, se faz intensa alusão à união dos italianos.

E, para consolidar os propósitos de nossa investigação, é no último verso [Estamos prontos para a morte, a Itália chamou (10)] que vemos claramente a presença de Pietas (devoção à Pátria), de Constantia (Serenidade, ainda que com risco de morte), de Disciplina (pela formação implacável) e de Gravitas (como o dever moral pela Pátria, sobre a si

${ }^{20}$ MAQUIAVEL, Nicolau. O Príncipe. Jardim dos Livros, 2008. 
mesmo).

Ainda dentro das virtudes romanas que auxiliaram a formação do Direito Romano e que forneceu o arcabouço para um melhor entendimento do contexto em que florira o Directum, tem-se a Simplicitas.

\section{II.3. Simplicitas}

Nas palavras de Giordani ${ }^{21}$ : a Simplicitas consiste em se valorizar "A qualidade do homem que vê claramente as coisas e as vê tais como são". Com essa definição de mestre, pode-se notar justamente aquela característica tão conspícua dos romanos: a praticidade.

Sabe-se que o olhar grego, já aqui mencionado, abriria um leque muito fértil aos estudos no campo da filosofia, sobre questões como: o que se vê? Como se vê? O olhar é condicionado?

Dificilmente um cientista social não seria tentado a especular os muitos vieses do assunto. De qualquer sorte, a "Apologia de Sócrates" é uma magnânima referência do pensamento grego sobre questões jurídicas ${ }^{22}$.

Importante que se ressalte ser a Simplicitas uma virtude, em que pese a análise de saber com clareza o que se vê. Advogaria por esse argumento, João Huss, que da chama clamara "Sancta Simplicitas"! ${ }^{23}$.

Apoiando essa visão, pode-se associar o que os romanos intitularam "Virtus", ou seja, o juízo e idealismo do indivíduo para com o discernir a água do vinho, os bons dos maus. O certo do errado. É o que a Lógica talvez traria em seus ensinamentos: atribuir valor lógico a um evento.

Além dos três princípios já vistos, apontados anteriormente como fundantes do Direito Romano (cf. GIORDANI, 1996), de muita importância seria complementa-los com outros fundamentos difundidos no Direito Moderno. Assim, teríamos os conceitos de "Fides" (suscintamente, Fé e Lealdade); a "Dignitas" (ou Vida Digna); o "Mores Maiorum" (conjunto de hábitos e costumes); o "Honestere Vivere" (Viver Honestamente); o "Alterum non Laedere" (Não Lesar a Outrem); o "Suum Cuique Tribuere" (Atribuir a

\footnotetext{
${ }^{21}$ GIORDANI, Mário Curtis. Iniciação ao Direito Romano. $3^{\text {a }}$ Ed. Editora Lumen Juris, 1996, p. 10.

${ }^{22}$ PLATÃO. Apologia de Sócrates. Nova Fronteira, 2017.

${ }^{23}$ PÖPPELMAN, Christa. Dicionário de Máximas e Expressões em Latim. Editora Escala. Traduzido por Ciro Mioranza, 2010, p. 113.
} 
cada um o seu Direito) $)^{24}$.

Finalmente, convém ressaltar, que a relevância dos princípios até aqui esboçados para o Direito Romano, para a ciência do Direito, em última análise, não tão somente dão conta do comportamento dos que lhes originaram, mas também do comportamento, dos hábitos, dos costumes dos povos que os aceitaram e até hoje os utilizam.

Não menos curioso é saber como teriam sido cunhados esses ideais. A origem da identidade do povo romano é absolutamente fundamental para o entendimento de toda a história do Império mais duradouro de todos os tempos, da história da Itália e do mundo, e especificamente para o Direito.

$E$ isto é salutar, na medida em que os primórdios dos princípios romanos vieram justamente durante o primeiro período de Roma, a Monarquia. Visto que foi neste período que ocorreu uma grande mistura e enriquecimento de culturas e costumes que assinaram a identidade dos romanos, nascendo daí, também, os costumes, as leis e os princípios do Direito Romano, tal como influências que transbordaram a seara do Direito.

Logo, uma breve análise da realeza de Roma, cujas contribuições marcaram definitivamente os rumos da península itálica e das regiões proximais, mostra que pelo menos dois outros povos foram muito importantes para a fase inicial da fundação da cidade e mesmo após do Império Romano.

Esta mescla enriquecedora enaltece a vastíssima cultura dos povos mediterrâneos e abre as portas para o entendimento do tempo presente, seja pelo aspecto jurídico, religioso ou de qualquer outra área.

\section{ROMA MONÁRQUICA: O INÍCIO DO DIREITO ROMANO}

\section{III.1. Origens das Instituições e Fontes da Roma Monárquica}

Aos que já pisaram na cidade eterna e experimentaram o sistema de metrô Romano, talvez se recordem de uma das estações que recebe o nome de "Re di Roma", a qual assim se intitula, como uma homenagem que se faz

\footnotetext{
${ }^{24}$ WARD, A., Heichelheim, F., Yeo, C. A History of the Roman People. $4^{\mathrm{a}}$ Ed. Nova Jérsei: Prentice Hall, 2003
} 
à memória dos Reis de Roma.

O marco da fundação de Roma é considerado datado por volta do ano de 754 a.C29. Inaugurando-se, assim, o período dos Reis de Roma. Ao todo foram sete reis: Rômulo, Numa Pompílio, Tulo Hostílio, Anco Márcio, Tarquínio o Prisco, Sérvio Túlio e Tarquínio o Soberbo.

Tito Lívio ${ }^{25}$ narra que Rômulo, consoante a famosa lenda da fundação Romana, era filho de Rhea Silvia e gêmeo de Remo. Pelo lado paterno, Rômulo e Remo eram filhos do Deus Marte (Ares, para os Gregos).

Pela linhagem materna, descendiam de Enéias de Tróia que, fugindo da destruição da llha pelos gregos, buscou refúgio em outros locais do mediterrâneo, tais como a Macedônia, a Sicília e, finalmente, o Lácio ${ }^{26}$.

Enéias casou-se com Lavínia, fundando, em homenagem à sua esposa, a cidade de Lavínia. Ascânio, filho e sucessor de Enéias, fundou Alba Longa, de forma que transferiu a sede do reino para esta cidade ${ }^{27}$. Em aproximados quatrocentos anos, sucederam-se treze reis, sendo o último dessa linhagem, Numitor, pai de Rhea Silvia.

\section{III.2. Numitor, a Loba e os gêmeos}

Numitor sofreu um golpe de Estado, engendrado pelo próprio irmão, Amulius. Preso, Numitor nada pôde fazer para evitar a condenação de sua filha Rhea à castidade, pois, por óbvio, Amulis temia alguma vingança da possível prole de Numitor.

Eis que, ao compasso da famosa lenda, o próprio Marte, Deus romano da Guerra, fez- se pai de Rômulo e Remo. Ao saber do ocorrido, temeroso, Amulis ordenou que as crianças fossem jogadas às águas do Rio Tibre. $\mathrm{E}$ assim, o fez. Devido ao fluxo do Rio Tibre - de correnteza bem conhecida os irmãos gêmeos foram depositados às suas margens. Uma loba as encontrou, amamentou e os criou até que um camponês conhecido como Fáustulo os avistasse. Nasce, então, da loba e dos irmãos gêmeos, um dos

\footnotetext{
${ }^{25}$ TITO LÍVIO, (27-25 a.C.). Ab Urbe condita libri. I.

${ }^{26}$ PEIXOTO, José Carlos de Matos. Curso de Direito Romano. Tomo I: partes introdutórias e geral. Rio de Janeiro: Renovar, 1997, p. 14.

${ }^{27}$ Idem.
} 
símbolos mais conhecidos, não apenas na Itália, mas mundialmente ${ }^{28}$.

Mary Beard em sua obra, explica que o termo Lupa, que o italiano herdou do latim como "loba", também era designado para as mulheres que se entregavam à prostituição. Portanto, remanesce uma divisão de opiniões acerca desta citação de Tito Lívio, mesmo acerca de uma história lendária ${ }^{29}$

Aos que desejam o deleite de ver o símbolo em escultura, é possível encontrá-lo em toda a Itália, especialmente próximo aos grandes e incontáveis monumentos e pontos turísticos da península italiana. A Galleria degli Uffizi, em Florença, os Museus Vaticanos e, em Roma, em vários locais, e.g., o Coliseu Romano.

Devido a uma discussão com a população, Remo acabou sendo denunciado ao rei Amulis que, por conseguinte, o aprisionou. Rômulo, tomando ciência do ocorrido, sem prejuízo de como foram recebidos pela loba e Fáustulo, decidiu ir ao resgate do irmão e de seu avô, ainda preso, o Rei Numitor.

Rômulo liberta seu irmão e seu avô, assassinando Amulius. Da liberdade de Numitor e Remo e do sangue jorrado do carrasco Amulius, o avô de Rômulo concedeu o direito da construção de uma cidade às margens do Tibre, no monte Palatino.

Rômulo e Remo disputaram o trono da cidade. Remo acabou sendo assassinado pelo seu irmão - uma discussão histórica se inicia sobre as possíveis versões de como teria se dado esse episódio.

No entanto, Beard traz em sua obra as palavras de Horácio este episódio, como uma derradeira forma de exprimir um pouco sobre a "essência" dos romanos, algo que certamente influencia a elaboração e cunho de seus costumes e a Principiologia jurídica até hoje: "Amargo destino persegue os romanos, e o crime do assassinato de um irmão, desde que 0 inocente sangue de Remo foi derramado no chão para se tornar uma maldição dos seus descendentes" (Quintus Horatius Flaccus. In: BEARD, 2017, p. 67).

\footnotetext{
${ }^{28}$ Id. Ibidem op. Cit.

${ }^{29}$ BEARD, MARY. SPQR: Uma História da Roma Antiga. Editora Planeta, 2017, p. 55-62.
} 


\section{III.3. Rômulo, o primeiro Rei de Roma}

Rômulo, vitorioso e legítimo detentor do direito ao trono, demarcou o Pomerium, local sagrado da nova cidade. O novo e primeiro Rei, Rômulo, batizou a cidade: Roma: nasce a cidade eterna.

Outro povo habitante da península itálica, os Sabinos, declarou guerra contra os romanos. Ocorre que, numa tentativa frustrada de Rômulo desposar alguma mulher Sabina, o Rei de Roma decidiu, então, armar uma emboscada.

Segundo os historiadores Lívio e Plutarco, Rômulo propôs um festival para Netuno Equestre, convidando os povos vizinhos, tais como os Antemnos, os Crustumerinos, os Cenicenses e os Sabinos. Durante o festival, Rômulo ordenou aos romanos para que raptassem as mulheres sabinas ${ }^{30}$.

Este é outro episódio bastante debatido acerca do ocorrido após o sequestro das mulheres. O primeiro deles é se de fato teriam sido somente mulheres Sabinas. As mulheres teriam sido estupradas e/ou molestadas por qualquer violência? A primeira união entre o primeiro Rei de Roma teria sido realizada pela força? Beard aponta a hipótese do estupro, enquanto que os historiadores antigos que divulgaram a lenda refutaram qualquer violência (BEARD, 2017, p. 61).

Deste evento, naturalmente, houve resposta por parte dos povos conquistados. O primeiro dos povos a iniciar uma guerra contra os romanos foram os Cenicenses, os quais foram derrotados facilmente. Também sucumbiram diante de Roma os Antemnos e Crustumerinos.

Tito Tácio, Rei dos Sabinos, invade Roma, com um poder bélico superior aos povos supramencioandos, os teriam sido abatidos pelos romanos. Uma traidora de Roma, chamada Tarpeia, facilitou a entrada dos Sabinos dentro do território romano. A traidora foi executada pelos próprios conterrâneos e arremessada no local outrora denominado Rocha de Tarpeia.

\footnotetext{
${ }^{30}$ PLUTARCO. Vida de Rômulo. TITO LÍVIO, Ad Urbe Condita.
} 
Para Marcus Terentius Varro ${ }^{31}$, a Rocha de Tarpeia, uma das sete colinas da Città Eterna, era $\mathrm{o}$ antigo nome do Monte Capitolino.

Com a deslealdade de Tarpeia, os Sabinos ocuparam Capitólio, sob o comando de Meto Cúrcio. Hosto Hostílio, que liderava as tropas capitolinas, fora assassinado pelos Sabinos, os quais forçaram os Romanos ao recuo frente ao Palatino. Rômulo, então, promete ao Deus Júpiter Estator, um templo, ao compasso da contra investida romana.

Os romanos começaram a inverter a situação, chegando Meto a fugir de batalha para não ser aniquilado. Eis que as mulheres Sabinas agiram como mediadoras, verdadeiras diplomatas, interferindo na batalha com tamanha eficácia que nesse ínterim, Romanos e Sabinos decidiram se aliar: Rômulo, Rei de Roma e Tito Tácio, Rei da Sabínia.

A unificação centralizou o poder em Roma, com Rômulo e Tito Tácio governando concomitantemente. Os Sabinos passaram a ocupar a região do Capitólio. Tito Tácio morreria cinco anos após a unificação, deixando um Rei soberano, Rômulo.

Rômulo foi o responsável pela criação do Senatus, cujos representantes eram escolhidos de acordo com a idoneidade e avançada experiência, além da opinião das cúrias romanas.

Uma cúria romana era uma subsecção das tribos que Ihe constituía. Três eram as tribos: os Ramnes de Rômulo, os Tities de Tito Tácio e os Luceres de, provavelmente Lucerus, o Etrusco (PEIXOTO, 1997, p. 14).

Os Sabinos e os Romanos ainda se desentenderiam por mais vezes ao longo da história. Há, realmente, um destaque para os Sabinos nessa Roma Monárquica. Não se pode olvidar que outros povos além dos Sabinos, dos Romanos, dos Custrumerinos, dos Cenicenses e dos Antemnos: existiram na península itálica, e sem muito esforço para mostrá-los: os etruscos. Contudo, em decorrência da participação dos Sabinos na constituição da Roma Antiga, faz-se mister conhecer um pouco mais sobre o povo da Sabínia.

${ }^{31}$ VARRÃO, Marco Terêncio (século I a.C.). De lingua latina. VI, 23. 


\section{III.4. Os Sabinos}

Os Sabinos habitavam a região central da atual Itália e, juntamente a outros povos, como os Marsos, incluídos num conjunto maior, denominado Sabélios.

Grandes historiadores divergiram sobre a origem dos Sabinos. Enquanto Plutarco considerava a região da Grécia como originária, Dionísio de Halicarnasso ${ }^{32}$ e Terentius Varro $^{33}$ defendiam a origem na própria península.

Os Sabinos se destacavam por apresentar ricos artefatos e relíquias arqueológicas de ouro e metais que valorizavam bastante. Conforme já visto, Tarpeia traiu os romanos facilitando a entrada sabina no Capitólio. Essa entrada teria sido em troca justamente de ouros e joias de valor.

No entanto, outro fator bastante recordado por Plutarco ${ }^{34}$ era a tendência belicosa dos Sabinos, assim como dos Romanos. Para o historiador, os Sabinos seriam descendentes de outro povo guerreiro, a saber, os Lacedemônios, da Lacônia, na região do Peloponeso, com capital em Esparta.

Tito Lívio menciona a possibilidade do costume dos Romanos de dar ao nascituro um nome e um sobrenome que tenha sido proveniente da cultura Sabina, principalmente devido ao fato de que o segundo Rei de Roma era um Sabino: Numa Pompílio, de Cures, a referida antiga capital dos Sabinos.

\section{III.5. Numa Pompílio}

Numa Pompílio foi nomeado o segundo Rei de Roma. Com a morte de Rômulo, viviam em terras romanas os dois povos unificados que, por razões políticas e diplomáticas, julgaram justo que o sucessor de Rômulo fosse de origem Sabina. Por conseguinte, buscaram tal homem, que deveria, consoante a sólida fama de moralidade dos Sabinos, ser um indivíduo de

\footnotetext{
${ }^{32}$ TITO LÍVIO. História de Roma. I.

${ }^{33}$ DIONÍSIO DE HALICARNASSO. Antiguidades Romana. I. 11 e 14, II, 49.

${ }^{34}$ PLUTARCO. Vidas Paralelas Rômulo. XV.
} 
respeito, princípios e valores éticos conspícuos ${ }^{35}$.

De Cures, Numa Pompílio assume o reinado de Roma. De natureza oposta ao seu antecessor, Rômulo, Numa se destacou por ser um rei pacífico, justo, religioso, sábio e com, por que não, um mais aflorado senso de justiça e igualdade ${ }^{36}$.

Numa Pompílio pode ser considerado, aos moldes de sua época, um rei bastante filantropo, vez que se preocupou com a condição dos escravos. Dentre as melhorias promovidas diretamente na vida destes, Numa autorizou que os escravos, assim como os seus patrões participassem do banquete festivo da Saturnalia, evento realizado em homenagem ao Deus Saturno.

O Deus Jano, responsável pelo início e pelas alterações (ideia cíclica de renovação) foi presenteado por Numa Pompílio com um templo e pela inclusão de um mês ao calendário, Janeiro. O mês de Fevereiro também foi incluído, vez que o ano se iniciava em Março, de Marte (Deus da Guerra). A religiosidade de Pompílio era tamanha, que por meio de consultas "espirituais" de Egéria, a Ninfa, analisava quais dias do ano eram ou não dias bons. Nos dias ditos ruins, havia proibições sobre certos atos da vida cível, tal como hoje a definimos ${ }^{37}$.

Durante o reinado de Numa Pompílio, era estritamente proibido qualquer representação por imagens dos Deuses. A convicção do segundo Rei de Roma era de que seria uma afronta gravíssima tentar representar por mãos humanas as divindades.

Neste átimo, é interessante que uma observação bastante pertinente seja promovida. Vê-se, pela lenda de Rômulo e Remo, que os irmãos gêmeos foram lançados ao rio. Para os versados e também para os que tenham a mínima instrução teológica cristã, é natural que se desponte a imagem de um cesto, aos sabores da deriva, do menino Moisés. A razão do despejo às águas é mutuamente semelhante, ambos os Reis temiam por seus tronos e ambos acabaram destituídos.

Há também a questão da representação das imagens, proibidas por grande parte do Credo Cristão e por Numa Pompílio. Destarte, ao curioso e

\footnotetext{
${ }^{35}$ PLUTARCO. A Vida de Numa Pompilio. p. III. 4

${ }^{36}$ Idem. P. III. 3

${ }^{37}$ TITO LÍVIO. Ab Urbe Condita Libri. p. I. 19.
} 
perquiridor resta refletir: há alguma influência na elaboração dos textos? Há uma coerência, aos moldes da convergência da coletividade em determinadas ações, reiteradas em uma dada época? O comportamento dos Romanos, assim como dos Egípcios em tela, seria da mesma verve?

Numa Pompílio também criou o instituto das Virgens Vestais, que zelavam pelo fogo sagrado. Criou, também, o Colégio dos Pontíficies, pelo qual a vida pública e privada deveria ser alinhada aos preceitos religiosos. Instituiu os Sacerdotes Sálios, que determinavam a separação dos tempos de paz e guerra no calendário, em que o período de guerra estava entre Março e Outubro ${ }^{38}$.

Com Numa Pompílio, surgiu o Colegiado dos Feciais, que cuidavam de conflitos vizinhos e guerras, sempre em última ratio. O Colégio em questão atuava, por assim dizer, de forma diplomática, enquanto os Pontíficies possuíam a essência da Magistratura, justamente pela avaliação e pelo julgamento dos atos públicos e privados ${ }^{39}$.

O mais pacífico e religioso dos reis de Roma era nascido, como já dito, em Cures, em Fara in Sabina, comuna italiana da região do Lácio. O ilustre José Peixoto menciona que os habitantes de Roma, desde a unificação Sabino-Romana, eram chamados de quirites, em provável homenagem à Cures ${ }^{40}$.

Ainda, dentro da grandeza de Roma, o Janículo, local de onde se pode ter uma panorâmica da cidade, foi onde os quirites ofereceram um mausoléu para Numa Pompílio, um rei que, entre dois povos de natureza belicosa, reinou pela paz. Dentre suas filhas, há, em especial, uma que merece destaque: Pompília.

Pompília desposara Marcio, trazendo ao mundo Anco Marcio. O marido de Pompília seria derrotado na disputa ao trono por Tulo Hostílio, o sucessor de Numa.

\footnotetext{
${ }^{38}$ PLUTARCO. A Vida de Numa Pompilio. P IX. 5.

${ }^{39}$ PLUTARCO. A Vida de Numa Pompílio. P. IX 1-4.

${ }^{40}$ PEIXOTO, José Carlos de Matos. Curso de Direito Romano. Tomo I: partes introdutórias e geral. Rio de Janeiro: Renovar, 1997, p. 15.
} 


\section{III.6. Tulo Hostílio}

O reinado de Tulo foi incisivamente marcado por guerras, dentre as quais, uma contra Alba Longa. Uma guerra que terminou com a conquista dos Romanos sobre os Albaneses. O rei, diferentemente de Numa Pompílio, mas muito semelhante ao pioneiro Rômulo, promovia diversas guerras e conflitos, inclusive contra os povos de Veios e Fidene. Por trinta e dois anos, guerreou contra os Sabinos.

A eleição de Tulo Hostílio como rei de Roma se deu por duas razões: era um Romano, vez que sucederia a um Sabino. E, seu avô, Osto Hostílio, lutara ao lado de Rômulo, exatamente contra os Sabinos ${ }^{41}$.

Extremo oposto de Numa, Tulo Hostílio não se dedicava às adorações religiosas, tampouco se preocupava com isso. Acredita-se, assim, que, por castigo divino, tenha sido fulminado por um raio.

Devido à religiosidade dos povos do antigo Lácio (Lazio), e não seria exceção, a urbe de Roma, os quirites entenderam a morte de Tulo Hostílio como um sinal de que o próximo rei deveria ser melhor, tal como fora Numa Pompílio. A Era de paz de Numa se findara com Tulo e, para agravar, o terceiro rei Romano gerou um conflito com os Sabinos ${ }^{42}$.

Durante a guerra Sabino-Romana do período de Tulo Hostílio, os Sabinos sofreram muitas perdas. Os Romanos já se firmavam como um povo belicamente mais desenvolvido. A causa da guerra teria sido que romanos teriam sido aprisionados no lado Sabino da cidade, e vice-versa.

Buscando amenizar a situação, buscaram a outro rei de sabedoria. Logo, ninguém melhor do que o próprio neto de Numa Pompílio para assumir, Anco Márcio.

\section{III.7. Anco Marcio, o último dos sabinos}

Anco Márcio foi, então, o quarto rei de Roma. Seu reinado também esteve tecido de pontos positivos. Além de promover relações de paz, apreço

\footnotetext{
${ }^{41}$ PEIXOTO, José Carlos de Matos. Curso de Direito Romano. Tomo I: partes introdutórias e geral. Rio de Janeiro: Renovar, 1997, p. 15.

${ }^{42}$ GILBERT, John (1978). Mitos e lendas da Roma Antiga. $2^{\mathrm{a}}$ ed. São Paulo: Melhoramentos, p. 72.
} 
pela religiosidade e preocupação pela qualidade de vida dos seus súditos, Anco também iniciou obras da esfera das engenharias sobre as águas.

Enquanto até agora as obras de engenharia e arquitetura se voltavam para a construção de templos e semelhantes, com Anco Márcio uma positiva inovação pôde ser adicionada ao rol da cidade.

Anco construiu o Porto de Óstia ${ }^{43}$ e a famosa Ponte Sublício (Ponte de Aventino) sobre o Rio Tibre, ligando a Piazza Dell'Emporio até a Piazza Di Porta Portese. A ponte era construída em madeira, sobre estacas de mesmo material. Promoveu o desenvolvimento da agricultura e construção de aquedutos.

A única guerra em que Anco Márcio se envolveu foi contra a invasão dos Latinos, os quais, derrotados, foram incorporados ao território romano.

Os quatro primeiros reis de Roma foram provenientes da etnia romana, Rômulo e Tulo Hostílio, e Sabina, Numa Pompílio e Anco Márcio. O sucessor de Anco, no entanto, era um rei de um povo também muito influente na península itálica, os Etruscos.

\section{III.8. Os Etruscos}

O povo etrusco também merece um posto especial nos livros de História. Trata-se de uma civilização originária da atual Toscana, Itália. Um povo de características bastante orientalizadas, o que divide os historiadores acerca da formação da etnia etrusca. No entanto, é cediço que se tratava de um povo muito desenvolvido aos padrões de então, com uma cultura definida, a qual, infelizmente, se extinguiu.

A outrora Etrúria se expandiu. Muitas cidades foram fundadas e tomadas pelo movimento expansionista dos Etruscos, e. g., Veios e Tarquínia. É muito importante frisar que os Etruscos eram povos muito habilidosos na arte da guerra, de forma que a ampliação de seu território serviu de plena prova, e que suas habilidades no comércio e artesanatos

\footnotetext{
${ }^{43}$ Idem.
} 
eram exponenciais ${ }^{44}$.

Romanos e Sabinos, até o momento, mostraram-se os mais capazes nos quesitos bélicos, contudo, o povo etrusco realmente se uniria ao seleto grupo de potências do território da bota. Cidades inteiras foram tomadas e destruídas pelos Romanos (vide Alba Longa) ${ }^{45}$. Os Sabinos ofereceram grande resistência, mas novamente os romanos saíram vitoriosos. Os Etruscos também fracassaram contra o povo de Roma.

Algumas peculiaridades do povo etrusco são bastante notáveis dentro do panorama traçado das civilizações itálicas de então. Também conhecidos como Tirrenos, possuíam sofisticadas técnicas para a elaboração de esculturas, artefatos e joias, com materiais variados: pedras, metais, inclusive o ouro ${ }^{46}$.

Diferenciavam-se de todas as demais civilizações itálicas pelo seu idioma único ${ }^{47}$, o que ainda confunde os sistematas quanto a sua classificação no tronco indo-europeu. Suas vestimentas também se apresentavam com peças diferentes, tais como os lenços e as túnicas.

A religiosidade também poderia ser considerada como muito influente, pois os Etruscos eram muito preocupados com a destinação do cadáver, seja pelo zelo ao corpo ou pela própria cremação. Em contramão dos Gregos e Romanos, os Etruscos evidenciavam as mulheres - já esculpidas e registradas com uma anatomia mais próxima dos egípcios - em nível de igualdade para com os homens ${ }^{48}$.

Aparentemente isso não era bem visto aos olhos da maioria dos povos, o que incitou o rótulo da promiscuidade aos tirrenos, onde mulheres detinham direitos tais como os homens e podiam participar até mesmo de festas e banquetes.

Mas, o mais interessante dos atributos dos Etruscos, era justamente o fato de que, como bons comerciantes, carregavam os dotes do

\footnotetext{
${ }^{44}$ DOWDING, JANKA. The Elusive Etruscans: The Quest for the Origins of the Etruscan Civilization. - Hirundo - The McGill Journal of Classical Studies, 2006-2007, v. 31-36.

${ }^{45}$ BARTOLONO, GILDA. The Villanovan Culture: at the beginning of Etruscan history. In: Turfa, Jean MacIntosh (ed.). The Etruscan World. Routledge, 2014, p. 79-98.

${ }^{46}$ Idem.

${ }^{47}$ HUNTSMAN, Theresa. Etruscan Language and Inscriptions. In: The Metropolitan Museum of Art. Heilbrunn Timeline of Art History, 2000.

${ }^{48}$ CARTWRIGHT, MARK. Etruscan Society. Ancient History Encyclopedia. Acesso em: 14/02/2017.
} 
convencimento. Por vias deste ofício, e de casamentos entre as famílias mais abastadas da Etrúria e Roma, os tirrenos se instalaram na urbe de Rômulo.

Um estrusco de nome Lucumo, quando em Roma: Lucius Tarquinius, de família muito rica, convenceu os Romanos de que deveria ser o novo rei, apelando pela imaturidade dos candidatos (filhos de pouca idade de Anco Márcio) e pelo seu histórico de riqueza.

\section{III.9. A Dinastia Tarquínia: Tarquínio Prisco, o primeiro Etrusco}

O quinto rei de Roma foi, então, Tarquínio Prisco, o qual prosseguiu com as conquistas e submissões de novas tribos, bem como importou consigo a religiosidade e crenças dos Etruscos para o povo Romano. Casouse com Tanaquil, ventilou as tradições de sua origem, construiu templos de adoração, tal como o de Júpiter, levantou também o Circo Máximo, para o provimento dos jogos, continuou a fortalecer o Senado e construiu uma elaborada rede de esgotos, conhecida como Cloaca Máxima ${ }^{49}$.

O primogênito de Anco Marcio, sentindo-se traído pela postura de Tarquínio Prisco, ao se apossar de seu trono legítimo, elaborou uma emboscada pela qual o primeiro rei etrusco de Roma fora assassinado.

Todavia, sem sucesso. Tanaquil, viúva de Tarquínio Prisco fez jus ao sangue etrusco e, com uma manobra de mestra, frustrou os filhos de Anco Marcio e promoveu a linhagem Tarquínia.

Tanaquil, ao perceber das intenções dos filhos de Anco, em especial, o filho de mais idade, em ocorrendo o assassinato do marido, mentiu para o povo romano de que o rei Tarquínio adoecera, de forma que por ordem da realeza haveria um substituto às suas atividades, até que sua doença e convalescença findassem.

O suposto substituto real era filho de Tarquínio com outra mulher, que realizava serviços para o rei. Tanaquil, assim, assegurava o sangue da Dinastia Tarquínia, por meio desta criança. De origem humilde, cujo nome era Sérvio Túlio ${ }^{50}$, veio a continuação dinástica.

\footnotetext{
${ }^{49}$ DIONÍSIO DE HALICARNASSO. Das Antiguidades Romanas. III, 49.1.

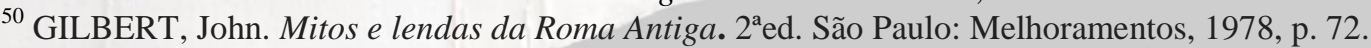




\section{III.10. Sérvio Túlio}

Poucos dias após Sérvio Túlio assumir o reino de Roma, Tanaquil declarou a morte de Tarquínio Prisco, dando legitimidade a Sérvio Túlio ser o sexto rei de Roma, sendo o segundo etrusco. Para garantir a Dinastia Tarquínia, a filha de Prisco com Tanaquil, foi dada em casamento ao rei Sérvio Túlio, de forma que a população de então cria fortemente na versão contada por Tanaquil. Novamente, verifica-se a habilidade dos tirrenos na arte do convencimento.

O reinado de Sérvio Túlio abrigou algumas reformas significativas. Inicialmente, a construção das primeiras muralhas de Roma, a famosa Muralha Serviana. Muito irônico e interessante o fato de que as muralhas são reconhecidamente consideradas como formas de proteção e isolamento e, atualmente, boa parte da Muralha Serviana deu lugar a uma estação ferroviária de Roma, cuja principal função é justamente propiciar o transporte e acesso entre as pessoas. O nome da estação é Roma Termini, uma das maiores da Europa.

Reformulou a divisão das tribos romanas, de sorte que passaram a existir quatro tribos na urbe: Palatina, Esquilina, Suburana e Colina. Em termos de estratificação social, o critério para a criação das classes foi a renda. Os patrícios foram fortalecidos, enquanto que os plebeus também adquiriram direitos, como acesso às forças militares ${ }^{51}$.

Cretella ensina que Sérvio forneceu também o direito de comércio aos plebeus. Ocorre que se todos recolhiam impostos, era justo que todos pudessem assim girar o dinheiro pelas vias do comércio. Foi assim uma reforma financeira, além de militar ${ }^{52}$.

Como era de esperar dos Etruscos, houve ampliação do comércio romano. Além disso, enquanto os patrícios faziam as leis por meio da Cúria, agora os plebeus adquiriram também o direito da feitura das leis, no entanto, por meio da Centúria.

O primeiro recenseamento documentado na história se deu por Sérvio

\footnotetext{
${ }^{51}$ Idem, p. 81.

${ }^{52}$ CRETELLA, JÚNIOR. Curso de Direito Romano - O direito romano e o direito civil brasileiro.

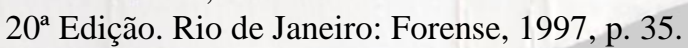


Túlio.

Sérvio foi assassinado por seu genro, que se casara primeiro com a filha mais velha e, quando do homicídio, com a mais nova, Túlia Minor. Era também um Etrusco e da linhagem de seu antecessor, seu nome: Tarquínio Soberbo.

\section{III.11. Tarquínio Soberbo}

Tarquínio Soberbo foi um déspota, segundo Tito Lívio. Centralizando todo o poder em suas mãos, o que fez de melhor para os Romanos foi ampliar, terminar e levantar novas construções. Não é de se surpreender, vez que Soberbo degolou o próprio sogro e não via nisso talvez nada além de "o fim justifica os meios".

Com o pior reinado da Roma monárquica, perdendo guerras - algo incomum para seu povo - e sendo autor de diversos escândalos, não demorou muito para que os patrícios derrubassem seu trono.

Ocorre que através de uma aliança entre famílias patrícias de destaque, Soberbo foi deposto. Findara-se também, assim, o período monárquico de Roma, nascendo, em suma, a República.

\section{III.12. Da Religiosidade}

Verificou-se que, dentre todos os povos que contribuíram para a formação de Roma, foram os Sabinos os que forneceram reis que se ativaram mais para o desenvolvimento das crenças e das adorações religiosas.

Numa Pompílio e Anco Marcio foram reis conhecidos pela elevada sabedoria e também pelo grande zelo para com as questões da religiosidade primitiva. Assim, vemos contribuições diretas deste legado da realeza Sabina para com o Catolicismo Apostólico Romano, incluindo o Código de Direito Canônico, além também de contribuições que nutriram o Direito de forma geral.

Foi com Numa que se cunhou a ideia de Pontífice, a qual perdura até os atuais dias. Aquele indivíduo dotado de profunda moralidade e 
religiosidade é que seria também a melhor opção para conectar o mundo material com aquele que lhe sobrepõe. Uma espécie de julgador e ao mesmo tempo porta-voz dos Deuses. Conforme já mencionado, os atos da vida pública e privada eram julgados por esses "magistrados".

Muito importante salientar que esses Pontífices deveriam sempre considerar em seus julgamentos a religião. $O$ peso que essa consideração exerce é assombrosamente grande: de seu surgimento, milênios após, ainda persiste. Para corroborar esse legado da realeza romana, verifica-se que existe, na Igreja Católica Apostólica Romana, uma hierarquia muito rígida.

Os Leigos - Laos Theon - são a base da pirâmide, seguido do Diaconato. Estes últimos, além de celibatários, são temporários ou, podem se tornar permanentes. Trata-se do único cargo da Ecclesia Romana que admite o matrimônio. No entanto, quando nomeado Diácono da Igreja de Roma, sendo solteiro, estará proibido de se casar.

Acima do Diaconato, seguem as ordens celibatárias: Presbiterato (vigários, padres), Bispado (Diocesano, Titular), Arcebispado, Patriarcado, Cardinalato e Papado.

O Papa, líder máximo da Igreja Católica Apostólica Romana, também conhecido como o Bispo de Roma, é o Sumo Pontífice. Apoiado pela Infalibilidade Papal, do Concílio Vaticano I, para o Catolicismo Romano, é o líder supremo e representante de Cristo, detentor das Chaves de Pedro Apóstolo na Terra.

Dessa maneira, concentrou durante séculos um poder que deixou reis de joelhos. Atritos surgiram durante a História, sejam conflitos internos dentro da própria instituição ou pelo choque contra o poder Temporal. Ocorre que a figura mais recente do Vigário de Cristo perdeu a força política que tinha, restringindo-se na esfera espiritual, de forma a também enfrentar o crescimento do Protestantismo e outras religiões dissidentes.

Mas, o válido, é que a essência e origem da figura Papal é aquela proposta por Numa Pompílio. O caráter de dualismo entre o poder religioso e o temporal, a cruz e a espada estiveram por muito tempo nas mãos do Bispo de Roma. Tanto é que o símbolo das duas chaves da Igreja representa exatamente isso: a chave prata, o poder temporal e a chave dourada, o poder 
espiritual ou religioso.

Uma visão que fora instituída como uma lei gerou também um costume desde os povos antigos sob essa égide. Eis aí uma influência direta da realeza de Roma para com a Igreja Católica Apostólica Romana e, consequentemente, no Direito Canônico.

Outra característica bastante interessante que pode ter influenciado a principal religião da Itália se iniciou com as Virgens Vestais. Essas virgens eram sacerdotisas da Deusa Vesta. Em, assim sendo, deveriam buscar os atributos de Vesta. Logo, a virgindade era fundamental e deveria ser seguida à risca, sob pena de morte, caso houvesse mácula.

O fogo sagrado da cidade restava sob seus cuidados, devido ao fato de serem as Virgens Vestais puras. O fogo era também símbolo de algo imaculado e puro. A analogia em tela é justamente da associação da ideia da pureza pela Virgindade, tal como a Virgem Maria, a virgindade exigida pelos votos de castidade das Freiras, a visão da Igreja sobre a virgindade e o matrimônio.

Por evidente que a moralidade de um determinado povo constitui uma relação biunívoca com a(s) religião(ões) da mesma nação. Assim, analisando as crenças religiosas, abre-se a possibilidade de inferir determinados dados sobre a moralidade daquela nação.

Tratava-se de um povo bastante heterogêneo quando considerados pelas características físicas e culturais, mas que, ao longo da evolução romana, acabaram criando certa identidade. Pois se viu que havia ali muito de militarismo e também de uma moralidade arraigada em preceitos religiosos.

Assim, numa observação ainda bastante precoce, torna-se muito difícil traçar um padrão ou perfil daquela civilização, aos moldes do embate Epicuristas $\times$ Estoicistas. No entanto, a praticidade da cultura romana já produzia efeitos. Esses efeitos perduraram, tal como a reza das missas em Latim, de forma que a grande maioria dos ouvintes sequer conseguia entender o mais básico do idioma. Algo que primava pela liturgia e ritualística acima de qualquer reflexão mais profunda. Esses efeitos práticos serão observados também dentro da elaboração e aplicação das leis, de uma 
maneira bastante literal. Os costumes, então, passam a ter seu primeiro ponto de partida - a busca pela eficiência, sem muitos questionamentos, e seu ponto de referência - o resultado prático, aplicado.

Verifique-se, pois, um exemplo de leis formuladas pelos povos itálicos da Idade Antiga.

\section{II.13. Ivs Civile Papirianvm}

Bastante debatido sobre em qual momento histórico o Jus Civile Papirianum teria sido apresentado por um Pontífice, o chamado Sexto Papirius. Esse documento consistia em um conjunto de leis que eram mais atinentes aos preceitos e costumes religiosos do que se pensar em Direito Romano. Pompônio foi bastante claro ${ }^{53}$ :

Depois de certo modo crescida a civitas, conta-se que o próprio Rômulo dividiu a civitas em trinta partes, as quais denominou cúrias, pelo fato de que naquele tempo ele administrava a Res-pubblica, por meio do sufrágio de suas partes. E, assim, certas leis curiata,s ele próprio deu ao povo: deram-nas também os reis seguintes. Todas elas permanecem escritas no livro de Sexto Papírio, um dos principais varões, o qual viveu no tempo de Soberbo, o filho de Demarato de Coríntio. Este livro, como dissemos, chamase ius civile Papirianum, não porque Papírio tenha acrescentado ali algo de seu, mas porque colecionou em um livro as leis proferidas sem ordem.

O que se discute é se tal documento teria sido emitido ainda no

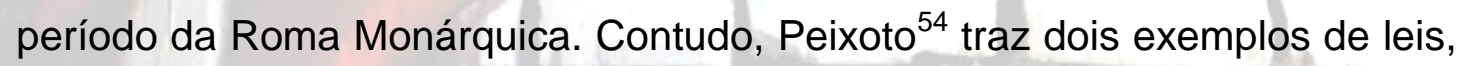
que demonstram a mentalidade dos Romanos de então, foram criadas durante o reinado de Rômulo, pelo próprio fundador da urbe eterna.

Uma lei se tratava do poder do pai (Pater) decidir sobre a vida de sua prole. O genitor detinha o direito de retirar a vida dos próprios filhos. Pode-se observar que as civilizações primitivas não se apegavam tanto aos filhos como atualmente. Em Esparta, crianças que apresentavam alguma

53 DA SILVA, Claudio Henrique Ribeiro. Direito Romano Arcaico Parte III. O Direito Secreto, p. 02.

${ }^{54}$ PEIXOTO, José Carlos de Matos. Curso de Direito Romano. Tomo I: partes introdutórias e geral. Rio de Janeiro: Renovar, 1997, p. 26. 
deficiência, eram eliminadas. O que realmente importava era o papel daquele futuro espartano na sociedade, principalmente em questões militares.

Há ainda a postura de eliminação de crianças, condição em que reis, faraós e líderes de então dispunham para proteger o trono de alguma ameaça. Extrapolando, coeteris paribus, se havia para alguns o direito de decidir sobre a vida dos próprios filhos, não soa estranho que um rei, soberano pudesse proferir o destino sobre a vida de todos de seu reino.

Vê-se também em mais de uma fonte, seja histórica ou teológica, assassinatos, genocídios, homicídios, traições, incestos, orgias, infanticídios, troca de favores, alianças de fachadas, guerras, conquistas entre tribos, submissões, instabilidade e atomicidade da formação dos povos e tribos e destaque para a figura masculina.

Neste palco, percebe-se que as cortinas se fecham, abrem-se, e o espetáculo segue o mesmo roteiro; mudam-se os atores, os diretores, o figurino, mas o roteiro sofre mudanças numa lentidão tristemente elevada.

A segunda lei de Rômulo proibia aos patronos e clientes de se acusarem mutuamente, sob pena da danação aos Deuses do Inferno. Já, a Virgem Vestal que perdesse sua pureza, seria enterrada viva.

Os Romanos, conta o professor Ribeiro da Silva, passaram por um breve período em que a escrita era considerada como algo ruim para a memória. Essa perspectiva se dá pelo fato talvez de que o exercício da memória seria afrouxado, vez que esta memória estaria externada num documento escrito.

Entretanto, não demorou para que se começasse a escrever aquele conjunto de regras bastante relacionadas com costumes e ideais religiosos. Como medida paramétrica, a civilização do Egito Antigo, dentre outras, possuíam os escribas para desempenhar tal função.

Ainda de acordo com o professor Ribeiro, um marco inicial para o Direito Romano seria o lus Flavianum, posto que o Direito era algo restrito a um conjunto elitista, detentores desses conhecimentos, geralmente sacerdotes, restando aos demais apenas o recebimento dessas aplicações. Pompônio, in verbis: 
Postea cum Appius Claudius proposuisset et ad formam redegisset has actiones, Gnaeus Flavius scriba eius libertini filius subreptum librum populo trdidit, et adeo gratum fuit id munus populo, ut tribunus plebis fieret et senator et aedilis curulis. Hic líber, qui actiones continent, appellatur ius civile Flavianum, sicut ille ius civile Papirianum: nam nec Gnaeus Flavius de sua quicquam adiecit libro.

O excerto menciona que Ápio Cláudio furtivamente levou ao povo o lus Flavianum, ganhando bastante reconhecimento deste. O texto foi portado de forma intacta e integral, pela qual nada adicionou Ápio ao conteúdo ${ }^{55}$.

Com a destituição de Tarquínio Soberbo e a extinção da realeza, com a república nasceram novos institutos formais, bem como houve um grande impulso para a o desenvolvimento jurídico.

Surgiu a figura do Pretor. Trava-se de um magistrado que iria lidar com as questões de matéria cível, enquanto que o rex sacrorum era um rei religioso e o pontifex maximus lideraria o Colegiado dos Pontífices. A partir deste momento, a História de Roma segue com a República e Império, cultivando a semente do Direito Romano.

\section{III.14. O Direito Romano atemporal}

Diferentemente do legado jurídico de outras culturas que coexistiram com a Roma Antiga, o Direito Romano sobreviveu através dos milênios sofrendo relativamente poucas alterações, de forma que em muitos institutos continua intacto. A língua latina continua sendo a referência para as expressões de Direito e comete grande falha aquele que the atribuir o título de língua morta.

Cretella traz os institutos da hipoteca, comodato e penhor como exemplos claros do Direito Romano nos dias atuais. Ocorre que a organização e o pensamento dos romanos para as questões jurídicas e militares eram realmente salutares. $O$ volume de informações, de procedimentos, de cisalhamento de funções só aumentou com o tempo ${ }^{56}$.

\footnotetext{
55 DA SILVA, Claudio Henrique Ribeiro. Direito Romano Arcaico Parte III. O Direito Secreto. (Tradução de França Madeira.). III, p. 02.

${ }^{56}$ CRETELLA, Júnior. Curso de Direito Romano - O direito romano e o direito civil brasileiro. $20^{\mathrm{a}}$ Edição. Rio de Janeiro: Forense, 1997, p. 02-03.
} 
Ainda segundo Cretella, África do Sul e Escócia seguem a aplicação quase integral do Direito Romano, provando estar vivo desde sempre. Raymond Monier ${ }^{57}$ ensina que:

O espírito de todo curso de direito romano não deve ser puramente histórico: deve ser ao mesmo tempo, prático, no sentido de que não basta estudar o direito romano em si mesmo, desde a fundação de Roma até a época de Justiniano. É preciso, sendo o caso, seguir o traço de instituições romanas até nossos dias.

O Direito Romano é, assim, constante objeto de estudo e uma importantíssima referência para os demais Direitos, além de regimento para muitos povos durante toda a História.

\section{CONCLUSÃO}

Decorrente de uma hermenêutica bastante sinérgica acerca da História da civilização romana e italiana, dos costumes e princípios norteadores do Direito em tela, do enriquecimento multifatorial exercido de forma direta e indireta na Roma Antiga por povos locais, bem como por Gregos e civilizações mediterrâneas, pode-se inferir que os primórdios do Direito Romano são provenientes de uma herança complexa, tendo como expoentes os povos da própria Roma, os Sabinos, os Etruscos e os Gregos.

Ressalte-se que, ao decorrer da História de Roma, conspicuamente após o término do período monárquico, o engrandecimento e o fortalecimento do Direito Romano tomaram proporções gigantescas, tangenciando o surreal. Tanto o é que, a instituição do latim como idioma oficial e amplamente empregado, desde o vulgar quanto à forma culta e o eclesiástico, dentre outras, não foram abordados nesta obra, justamente pelo foco estar num momento mais primitivo, de surgimento, de fundação de Roma e de todo o seu legado jurídico e cultural.

${ }^{57}$ MONIER, Raymond. Manuel élémentaire de droit romain. $6^{\mathrm{a}}$ ed., 1947, vol. I. p. 03. 


\section{REFERÊNCIAS ADICIONAIS}

ADKINS, L. and Adkins, R. Dictionary of Roman Religion. Nova lorque: Oxford University Press, 2000.

APPUZO, Michael L.J. M.D. Gravitas, Severitas, Veritas, Virtus. Neurosurgery: August 2006, v. 59, issue 2, p. 219-221.

BARTOLONO, GILDA. The Villanovan Culture: at the beginning of Etruscan history. In: Turfa, Jean MacIntosh (ed.). The Etruscan World. Routledge, 2014.

BEARD, MARY. SPQR: Uma História da Roma Antiga. São Paulo: Editora Planeta, 2017.

BERGER, Adolph. Encyclopedic Dictionary of Roman Law. Filadélfia: The American Philosophical Society, 1991.

CARTWRIGHT, MARK. Etruscan Society. Ancient History Encyclopedia. https://www.ancient.eu/user/markzcartwright. Acesso em 17/09/2018, às 12:05 horas.

CÍCERO

De

Natura

Deorum. http://www.dominiopublico.gov.br/pesquisa/PesquisaObraForm.do?select action\&co autor= 174. Acesso em 17/09/2018, às $11 \mathrm{~h}: 51 \mathrm{~min}$.

COARELLI Filippo. I Santuari, I fiumi, Gli Empori. XIII. Storia Einaudi dei Greci e dei Romani, 2008.

COLLINS, Willian et al. Collins Spanish Dictionary. Harper, 2006.

COLLINS, Willian et al. Collins Italian Dictionary. Harper, 2007.

CRETELLA, Júnior. Curso de Direito Romano - O direito romano e o direito civil brasileiro. 20를 Edição. Rio de Janeiro: Forense, 1997.

CRUZ, Sebastião. Jus Derectum (Directum). Coimbra, 1971. Apud FERRAZ Jr., T.S. Introdução ao Estudo do Direito. São Paulo: Atlas, 1988.

DA SILVA, Claudio Henrique Ribeiro. Direito Romano Arcaico Parte III. 4.3. O Direito Secreto. Disponível em: www.ribeirodasilva.pro.br/direitoromanoarcaicoparte03-02.html. Acesso em 17/09/2018, às $11 \mathrm{~h}: 31 \mathrm{~min}$.

DE PLÁCIDO E SILVA. Vocabulário Jurídico. 31를 Edição. Rio de Janeiro: Editora Gen / Forense. 2014.

DINIZ, Maria Helena. Código Civil Anotado. São Paulo: Saraiva, 2003. Apud VIVIAN, Wilson A. B. Princípio Alterum non Laedere (Nenimen Laedere), dignidade humana e boa-fé. 2015. Disponível em: https://jus.com.br/artigos/35605/principio-alterum-non-laedere-neminemdignidade-humana-e-boa-fe. Acesso em 17/09/2018, às 11h:33min. 
DIONÍSIO DE HALICARNASSO. Antiguidades Romanas. http://penelope.uchicago.edu/Thayer/E/Roman/Texts/Dionysius of Halicarnas sus/home.html. Acesso em 17/9/2018, às 11h:50min.

DOWDING, JANKA. The Elusive Etruscans: The Quest for the Origins of the Etruscan Civilization - Hirundo. The McGill Journal of Classical Studies, 20062007.

FESTO, Pompeu. Istituzioni di Diritto Romano. Tradução italiana.

GILBERT, John. Mitos e lendas da Roma Antiga. $2^{\text {a }}$ ed. São Paulo: Melhoramentos, 1978.

GIORDANI, Mário Curtis. Iniciação ao Direito Romano. 3ª Edição. Editora Lumen Juris, 1996.

HOUAISS Antonio, Villar, Mauro de Salles. Houaiss, Dicionário de Língua Portuguesa. Editora Objetiva, 2009.

HUNTSMAN, Theresa. Etruscan Language and Inscriptions. In: The Metropolitan Museum of Art. Heilbrunn Timeline of Art History, 2000.

JUSTINIANO, Digest. 1.1.10. In: Watson, Alan (ed.). The Digest of Justinian. Philadelphia: U. Pennsylvania, 1985.

LAROUSSE. Petit Dictionnaire de Français. Larousse. 2004.

MATEUS. Evangelho segundo São Mateus - Bíblia Sagrada. Sociedade Bíblica do Brasil. Barueri: Edição Bilíngue Chinês - Português, 2012.

MAQUIAVEL, Nicolau. O Príncipe. Jardim dos Livros, 2008.

MARROU. As Escolas Romanas. In: História da Educação na Antiguidade. São Paulo: Herder, 1966.

NISHITANI, Yuko. Introdução à História do Direito Japonês. Revista Cadernos do Programa de Pós-Graduação em Direito. Universidade Federal do Rio Grande do Sul, 2003.

PACCHIONI. Diritto Romano - I. Apud PEIXOTO, José Carlos de Matos. Curso de Direito Romano, tomo I: partes introdutórias e geral/José Carlos de Matos Peixoto. Rio de Janeiro: Renovar, 1997.

PEIXOTO, José Carlos de Matos. Curso de Direito Romano - Tomo I: partes introdutórias e geral. Rio de Janeiro: Renovar, 1997.

PLATÃO. Apologia de Sócrates. São Paulo: Nova Fronteira, 2017.

PLUTARCO. Vida de Rômulo. Domínio Público. Disponível em: http://www.dominiopublico.gov.br/pesquisa/PesquisaObraForm.do?select action\&co auto $\underline{r=174}$. Acesso em 17/09/2018, às 11h:54min. 
PLUTARCO. Vida de Rômulo. Domínio Público. Disponível em: http://www.dominiopublico.gov.br/pesquisa/PesquisaObraForm.do?select action\&co auto $\mathrm{r}=174$. Acesso em 17/09/2018, às 11h:54min. - Vidas Paralelas Rômulo. Domínio Público. Disponível em:

http://www.dominiopublico.gov.br/pesquisa/PesquisaObraForm.do?select action\&co autor=174. Acesso em 17/09/2018, às 11h:54min.

POLÍBIO. Histórias. Domínio Público: https://www.researchgate.net/publication/310312128 Polibio historia pragmatica Livros I a V Traducao introducao e notas por Breno Battistin Sebastiani 2016. Acesso em 17/09/2018, às $11 \mathrm{~h}: 59 \mathrm{~min}$.

PÖPPELMAN, Christa. Dicionário de Máximas e Expressões em Latim. Editora Escala: Traduzido por Ciro Mioranza, 2010.

SHINJITAI. Constituição do Japão, 1947.

TITO LíviO. Ab Urbe Condita Libris. Domínio Público: https://la.wikisource.org/wiki/Ab Urbe Condita. Acesso em 17/09/2018, às 11h:54min.

História de Roma. Domínio Público: https://la.wikisource.org/wiki/Ab Urbe Condita \%E2\%80\%93 Periochae. Acesso em 17/09/2018, às $11 \mathrm{~h}: 54 \mathrm{~min}$.

VADE MECUM. 18ª Edição, Saraiva, 2014.

WARD, A., Heichelheim, F., Yeo, C. A History of the Roman People. 4" Ed. Nova Jérsei: Prentice Hall, 2003. 